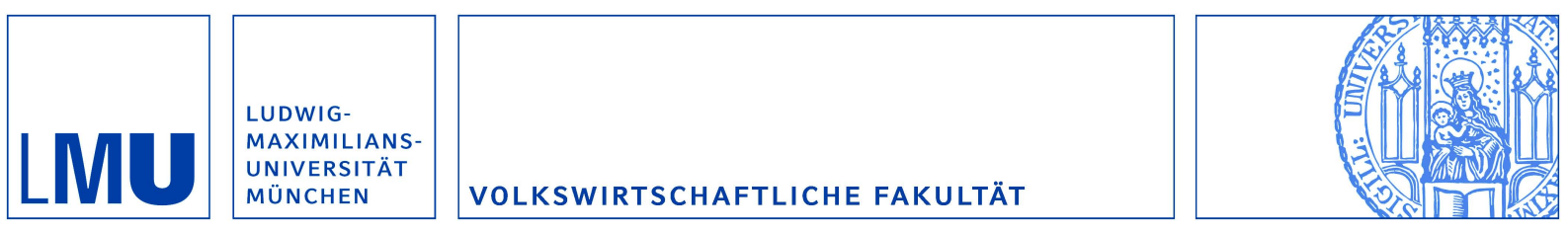

Traxler, Christian und Winter, Joachim:

Survey Evidence on Conditional Norm Enforcement

Munich Discussion Paper No. 2009-1

Department of Economics

University of Munich

Volkswirtschaftliche Fakultät

Ludwig-Maximilians-Universität München

Online at https://doi.org/10.5282/ubm/epub.8992 


\title{
Survey Evidence on Conditional Norm Enforcement
}

\author{
Christian Traxler* and Joachim Winter ${ }^{\dagger}$
}

First Draft: January 2008

This version: January 2009

\begin{abstract}
We discuss survey evidence on individuals' willingness to sanction norm violations such as evading taxes, drunk driving, fare dodging, or skiving off work - by expressing disapproval or social exclusion. Our data suggest that people condition their sanctioning behavior on their belief about the frequency of norm violations. The more commonly a norm violation is believed to occur, the lower the individuals' inclination to punish it. Based on an instrumental variable approach, we demonstrate that this pattern reflects a causal relationship.
\end{abstract}

JEL classification: K42; Z13; D1

Keywords: Norm Enforcement; Sanctioning; Social Norms; Survey Evidence.

${ }^{*}$ Corresponding Author. Max Planck Institute for Research on Collective Goods. Kurt-Schumacher-Str. 10, 53113 Bonn, Germany. Phone/Fax: +49 (0)228 91416-69/-62; E-mail: traxler@coll.mpg.de

${ }^{\dagger}$ Department of Economics, University of Munich, Ludwigstr. 28 RG, 80539 Munich, Germany. Phone/Fax: +49 (0)89 2180-2459/-3954; E-mail: winter@lmu.de 


\section{Introduction}

Over the last decade, a solid body of empirical research has documented the prevalence of conditional cooperation. People who follow this behavioral pattern condition their prosocial conduct on (their belief about) other people's inclination to act pro-socially. Among economists, conditional cooperation was first discussed in the context of experimental studies. ${ }^{1}$ The evidence from the lab was recently complemented by a series of field experiments, demonstrating that a significant fraction of individuals condition their public good contributions on others' behavior (e.g. Frey and Meier, 2004; Alpizar et al., 2008).

Conditionally pro-social behavior can be explained by the presence of social norms, i.e. rules of conduct which are enforced by internal or external sanctions (Coleman, 1990). ${ }^{2}$ An important assumption of the literature is that these sanctions depend on the level of norm adherence: the more people comply with a norm, the stronger are the sanctions for a norm deviation (see e.g. Lindbeck et al., 1999). Given this pattern, social norms can induce conditional norm compliance.

The present paper discusses survey evidence which confirms this sanctioning pattern. In a national survey conducted in Austria, respondents were confronted with eight different 'incorrect behaviors', including tax evasion, drunk driving, fare dodging or skiving off work. Respondents were then asked how they would react if an acquaintance followed such behavior. The response categories cover positive reactions - like approval (Rege and Telle, 2004) - as well as negative reactions like cooling down the contact or expressing disapproval. The latter represent norm enforcing sanctions which are well studied in experimental economics (Falk et al., 2005; Cinyabuguma et al., 2005). However, little is know about the pattern of social sanctions outside of the lab. ${ }^{3}$

We show that norm violations which cause the potentially largest negative externalities (e.g. drunk driving, speeding) are punished most frequently. Moreover, these behaviors are sanctioned independently of the respondents' beliefs regarding the pervasiveness of these norm violations. Our data therefore suggest that sanctions for the violation of 'strong norms'

\footnotetext{
${ }^{1}$ Compare Sonnemans et al. (1999), Keser and Van Winden (2000), Fischbacher et al. (2001), among others. Gächter (2007) provides a comprehensive survey of the literature.

${ }^{2}$ See Fehr and Schmidt (2006) for a review of different models that can explain conditional cooperation.

${ }^{3}$ A notable exemption is Dohmen et al. (2008) who study survey data on reciprocal behavior.
} 
are imposed unconditionally. For less strong norms, however, we find clear evidence on a conditional sanctioning pattern: individuals who consider a certain norm violation to be relatively rare are more prone to sanction this behavior. The pattern is particularly pronounced among individuals with higher levels of education.

One might argue that the correlation between beliefs and norm enforcement is simply driven by respondents who engage in some of these "incorrect behaviors" themselves and thus are not likely to punish these norm violations. At the same time, they may also (selfjustifyingly) believe that many other people engage in such behaviors. To exclude this possible explanation, we employ an instrumental variable approach. Our analysis shows that the link between beliefs about the frequency of norm violations and the inclination to punish such violations indeed reflects a causal relationship.

The paper is structured as follows. Section 2 discusses the norm violations addressed in the survey. Section 3 establishes our main findings and section 4 demonstrates the causality underlying conditional norm enforcement. We conclude with a discussion of potential policy implications.

\section{The Survey}

Our data stem from a study on TV licence fee compliance conducted by the Austrian Public Broadcasting Company in 2000. The survey was administered by a commercial survey organization, using computer-assisted personal interviewing. It was targeted at a random sample of the Austrian household population. From each household, the financial decision maker (defined as the one who is in charge of paying regular household expenditures like the rent or the electricity bill) was asked to answer the survey. The top panel of table 1 contains the socioeconomic characteristics of the respondents. To facilitate interpretation, all characteristics are grouped and coded as dummies. The sample is composed by $59 \%$ of females; slightly more than half of the respondents are older than 50 years. $55 \%$ have a college education, $19 \%$ hold a high-school or university diploma. $44 \%$ state that they have infrequent contact with their neighbors, every fifth has frequent contact.

Table 1 about here. 
In one section of the survey, respondents were confronted with eight different behaviors ('actions') which were described as "all incorrect but nevertheless occurring more or less frequently." 4

(1) Drunk Driving. Driving a car although one is aware of the fact that one has drunken too much and is clearly above the legal blood alcohol limit.

(2) Hazardous Waste. Putting hazardous waste like batteries or chemicals into the ordinary household rubbish (instead of a waste separation container).

(3) Speeding. Driving at $160 \mathrm{kmph}$ on an interstate highway (legal limit $120 \mathrm{kmph}$ ) or at $70 \mathrm{kmph}$ in a residential area (legal limit 50kmph).

(4) Stealing Newspapers. Stealing newspapers from pay-as-you-take news boxes.

(5) Skiving off Work. Pretending to be sick to stay away from work for one or two days.

(6) Evading TV Licence Fees. Not registering for TV licence fees.

(7) Fare Dodging. Travelling on public transport without a ticket.

(8) Evading Taxes. Hiring craftsmen from the shadow economy without paying taxes.

Among the eight actions, the first three potentially cause the most grave, negative externalities. The last three are different forms of evading taxes or other mandatory contributions to public goods. All behaviors constitute violations of Austrian laws. ${ }^{5}$ Most of these laws, however, are 'mild' in the sense that they are backed by non-deterrent legal sanctions (Tyran and Feld, 2006). Given that compliance with mild laws not only depends on formal law enforcement but also on "the informal enforcement of social mores by acquaintances, bystanders, trading partners, and others" (Ellickson, 1998; p.540), social sanctions might be crucial to deter non-compliance. This point has been stressed particularly in the context of tax compliance (see e.g. Alm et al., 1992).

\footnotetext{
${ }^{4}$ The original sequence of the behaviors in the survey was $2,4,7,6,8,5,3,1$.

${ }^{5}$ Austrian citizens are bound by law to bring hazardous waste to waste separation containers (action 2). On Sundays, Austrian newspapers can be bought from pay-as-you-take boxes; these boxes, however, have no lock which would prevent people from stealing the paper (action 4; for a related field experiment, see Pruckner and Sausgruber, 2008). In case of sickness, Austrian employees are allowed to stay at home for two days without any medical certificate of their sickness (action 5). Owners of operational TVs and radios must register their equipment and pay an annual licence fee of roughly Euro 250 (action 6; see Fellner et al., 2008).
} 
Respondents were then asked to state their beliefs about how widespread these behaviors are on a five-point Likert scale ranging from 'very infrequent' [1] to 'very frequent' [5]. The distributions of the responses are presented in the lower panel of table 1. The data show that the beliefs differ both, between individuals and between the different norm violations. For example, drunk driving and speeding (actions 1 and 3) are perceived to be more widespread than the evasion of TV licence fees (action 6).

Another question on the survey asked how the respondent would react if she learned that a close acquaintance has taken action 1, 2 and so on. The five response categories,

[ 1 ] "I would be impressed by him/her",

[ 2 ] "She/he should better not be caught",

[ 3 ] "I would not care",

[4] "I would seriously talk with him/her about this behavior and would try to convince him/her to stop doing it",

[ 5 ] "I would cool down the contact with him/her",

can be ordered from approval [1], (benevolently) ignoring it $[2,3]$, to sanctions in the form of expressing disapproval [4], or even exclusion [5]. The distributions of the responses are reported in table 4 .

Table 2 about here.

The data indicate that a majority would sanction an acquaintance for the first five actions - mostly by expressing disapproval rather than by cooling down the contact. More than $80 \%$ would punish the first two actions, still $66 \%$ would do so for action 3 . Hence, the social norms against these three norm violations - which are also those with the (potentially) most grave externalities - are particularity strong, in the sense that at least two-third of the respondents state that they will sanction them. Equivalently, one might call the social norms against the evasion of taxes and other mandatory contributions to public goods (actions 6-8) rather weak, since evasion behavior is only sanctioned by a minority: $50 \%$ and more would react with 
ignorance. Note that none of the eight behaviors meets with a significant share of approval. ${ }^{6}$ In line with our notion of strong and relatively weak norms, however, the approval is strongest for action 8: evading taxes by hiring labour from the shadow economy.

\section{Conditional Norm Enforcement}

How does sanctioning differ between individuals and how does it relate to their beliefs about the frequency of the different actions? We answer these questions by estimating ordered probit models. We assume that respondent $i$ has propensity $\widetilde{y}_{i j}$ to sanction action $j \in\{1, \ldots, 8\}$. These propensities are latent variables which are unobserved in our data. The observed dependent variables, the individual reactions $y_{i j} \in\{1, \ldots, 5\}$, are determined by the response model

$$
y_{i j}=\left\{\begin{aligned}
1 & \text { if } \\
2 & \text { if } \quad \lambda_{1 j}<\widetilde{y}_{i j} \leq \lambda_{1 j} \\
\cdots & \lambda_{2 j} \\
5 & \text { if } \lambda_{4 j}<\widetilde{y}_{i j}
\end{aligned}\right.
$$

and $\widetilde{y}_{i j}=\alpha_{j}$ Belief $_{i j}+X_{i} \beta_{j}+\varepsilon_{i j}$, where the vector $X_{i}$ contains the socioeconomic characteristics (see table 1) and $\varepsilon_{i j}$ is a random component which is assume to be i.i.d. normal across respondents $i$ and actions $j$, conditional on the covariates.

Our key explanatory variable is $\operatorname{Belief}_{i j}$, the individuals' belief about the frequency with which the different actions occur. Remember that higher values of $\widetilde{y}_{i j}$ represent a stronger propensity to sanction and that higher values of Beliefij mean that action $j$ is expected to be more common. Hence, if the severity of sanctions is declining (and accordingly, reactions are more positive) the more often a norm is violated - as it is assumed in the literature on social norms (Lindbeck et al., 1999) - we should expect negative coefficients for $\alpha_{j}$.

The results from our estimations are given in table 3 . The left part of the table presents

\footnotetext{
${ }^{6}$ While this might be driven by social expectations in the interaction with the interviewer, the fact that approval clearly differs for one action - nearly $5 \%$ state that they are impressed by a tax evader - suggests that, in principle, survey participants are prepared to reveal their approval of norm violations.
} 
the outcome for the full sample. ${ }^{7}$ Except for one behavior (action 2, hazardous waste), $\alpha_{j}$ has the expected negative sign. The coefficients, however, are only significant for the last five norm violations (actions 4-8). For these behaviors we find a clear pattern of conditional norm enforcement: the more widespread norm violation are believed to occur, the lower the individual's inclination to punish the behavior. For deviations from the three strong norms, the most frequently sanctioned actions $1-3$, we do not find a significant impact of the individuals' belief.

Table 3 about here.

A closer analysis of the data revealed that conditional norm enforcement is particularly distinct among those with intermediate and high education. To show this point, we replicate the estimations for a restricted sample which excludes individuals with low education. The results are reported in the right part of table 3. For violations of the two strongest norms, we find a weakly significant conditional sanctioning behavior for action 1 (drunk driving) and no significant effect for action 2 (hazardous waste). For the remaining six actions there is a clear conditional sanctioning pattern: the more rarely these norm deviations are expected to occur, the more severely they are sanctioned. This effect is significant at the $1 \%$ (actions 3 , 4, 6, 7 and 8) and 5\%-level (action 5), respectively.

Summing up our findings, we have shown that the response to deviations from strong norms (actions 1-3) seems to be unconditionally negative, whereas sanctions for violations of weaker norms are conditioned on the expected prevalence of the respective actions. Table 3 also suggests that conditional norm enforcement is more pronounced among the population with intermediate and high levels of education. This finding is consistent with the observation that conditional cooperation is particularly robust in lab experiments with student subject pools (see Gächter, 2007). The data further show that females tend to be more inclined to sanction, in particular deviations from the strong norms. In contrast, employed respondents are less engaged in sanctioning. All other socioeconomic characteristics do not show a clear-

\footnotetext{
${ }^{7}$ Item non-response and thus the number of observations differs somewhat between the eight actions (see also table 4). Estimating alternative model specifications which control for non-response on the belief question, showed that our findings are not affected by the non-responses. We also considered a different ordering of the two sanction-responses, we reduced the dependent variable from a five-point to a four- and three-point scale (pooling the two sanction-responses 4 and 5 as well as responses 1 and 2, respectively). Estimations using these alternative dependent variables yield results that are basically identical to those reported in table 3 .
} 
cut impact on sanctioning behavior.

\section{Causality of the Effect}

Let us now address an important concern regarding the causality in the link between individuals' inclination to sanction a behavior and their beliefs. One might argue that those who are prepared to punish a certain norm violation are also more likely to believe such violations happen only infrequently. ${ }^{8}$ For instance, if a person thinks that evading taxes is horrible, that influences her belief about who is doing such a horrible thing and also how she would sanction a tax evader. A different person, who considers evading taxes to be just a risky gamble and evades herself, might also believe that evasion is relatively frequent - eventually also to justify her own behavior - and will not impose sanctions on other evaders. Such mechanisms could, in principle, explain the findings from table 3. We will now provide evidence which rejects this possible explanation and confirms that the direction of causality is, in fact, as we argued above: because a behavior is perceived to occur more frequently, it is less likely to be sanctioned.

To make this point, we follow an instrumental variable (IV) approach. Our IV strategy makes use of data on the local level of TV licence fee evasion at the time of the survey. The level of evasion is estimated by the public agency governing TV licence fees, by comparing the number of households who are paying licence fees with the total number of households in a municipality. Given that nearly all Austrian households do hold a radio or a TV (and are thus liable to pay TV licence fees), the comparison provides a reasonable proxy for the true number of evading households. ${ }^{9}$

Our data contain information on the estimated evasion level in each of the 83 districts the respondents live in. The evasion level is classified in 5 categories, as presented in table 4. It turns out that individual beliefs about the pervasiveness of licence fee evasion - as well as the beliefs regarding four other norm violations - are strongly correlated with the evasion levels in the respective respondent's district. This suggests that the information on the local evasion behavior is crucial when individuals form beliefs on overall non-compliance levels.

\footnotetext{
${ }^{8}$ For a discussion of self-serving biases see e.g. Babcock and Loewenstein (1997).

${ }^{9}$ Compare Fellner et al. (2008) for more details on this institution.
} 
Table 4 about here.

In total, five out of the eight norm-violations addressed in the survey (actions 2, 4, 5, 6, and 7) are correlated with the estimated level of evasion. ${ }^{10}$ Hence, local evasion is a relevant instrument when we estimate the causal impact of beliefs on the individuals' willingness to sanction these five actions. This is also confirmed by the first-stage regression results, discussed below. The instrument is exogenous since licence fee evasion can safely be assumed to be uncorrelated with factors that influence the individuals propensity to sanction (at least for those norm violations that are unrelated to TV licence fees).

We implement IV estimation in a binary probit model. ${ }^{11}$ The dependent variable is the dummy $d\left(y_{i j}\right)$, indicating one if individual $i$ indicates to sanction behavior $j$ (respond in response categories 4 and 5 ). We estimate equation

$$
d\left(y_{i j}\right)=\alpha_{j}^{I V} \text { Belief }_{i j}+X_{i} \beta_{j}^{I V}+\epsilon_{i j}
$$

for $j \in 2,4,5,6,7$, where Belief $_{i j}$ is instrumented with the level of licence fee evasion, Evasion $_{i}$, in respondent $i$ 's district. The first-stage regression is given by

$$
\text { Belief }_{i j}=\gamma_{j} \text { Evasion }_{i}+X_{i} \delta_{j}+v_{i j}
$$

The results from (non-instrumented) probit and from IV probit estimations are summarized in table 4.

The probit estimations confirm the findings of the ordered probit models reported in section 3 above. On the one hand, the individual belief does not affect the propensity to sanction deviations from strong norms. This is reflected in the results displayed in column 1 of table 4, where the belief has no significant effect for the case of 'hazardous waste'. The effect remains insignificant in the corresponding IV probit estimation (column 2), where we instrument for the belief.

On the other hand, we do find a significant impact of the belief on the individual's

\footnotetext{
${ }^{10}$ The correlation of local licence fee evasion level with beliefs about other norm violations is in line with the recent evidence in Keizer et al. (2008).

${ }^{11}$ See Wooldridge (2002; section 15.7 .2$)$ for a discussion of instrumentals variables estimation of probit models.
} 
likelihood to punish the other norm violation - also when we instrument the potentially endogenous belief variables. For stealing newspapers and skiving off work, the belief has a highly significant, negative effect in the probit estimations (columns 3 and 5, respectively). The result is confirmed in the IV estimations. In columns 4 and 6 , the estimated coefficients of $\alpha_{j}^{I V}$ are significant at the 1-percent level. A similar picture emerges for licence fee evasion, with the estimated coefficient being significant at the 5 - and the 10-percent level in the probit and the IV probit estimations, respectively (columns 7 and 8). Finally, for fare dodging, the probit estimation does not show a significant impact of the belief (column 9), whereas the IV probit reveals a weakly significant effect.

Table 5 about here.

Regarding the performance of our instruments, the first-stage results displayed in table 4 indicate a strong partial correlation of our instrument, the local level of licence fee evasion, with the respective belief for the five actions. ${ }^{12}$ Finally, under the maintained assumption that the instrument is valid, we can test the hypothesis that the error terms in the main and the first-stage equation are uncorrelated. If this hypothesis cannot be rejected, the potentially endogenous variables in the main equation - the individuals' beliefs - are, in fact, exogenous. The Wald Test provides mixed results: for the strong norm (hazardous waste), there seems to be no endogeneity problem. Similarly, we can not reject the hypothesis for the last two norm violations (licence fee evasion and fare dodging). The test points to an endogeneity problem only for stealing newspapers and skiving off work, which justifies the potential critique that motivated our IV approach.

Summing up, the results establish a causal relation between beliefs and the propensity to sanction norm violations: the more frequent deviations from a norm are perceived to occur, the less likely they will get punished. Deviations from strong norms, however, are sanctioned unconditionally.

\footnotetext{
${ }^{12}$ One might question the exclusion assumption for the case of licence fee evasion, as the local evasion level might be an explanatory variable in the main equation. Note, however, that this concern does not affect the validity of our instrument for the other four norm violations under consideration.
} 


\section{Concluding Discussion}

The evidence from a national survey presented in this paper supports a central assumption of the literature on social norms: the strength of norm enforcing sanctions depends on the expected level of norm compliance. The more frequently deviations from a social norm are believed to occur, the less likely a norm violation is sanctioned. This pattern is most pronounced for relatively weak norms and among individuals with higher education. In contrast, deviations from very strong norms are punished independently of beliefs about others' norm compliance.

All eight behaviors which were considered in the survey correspond to law violations. Hence, our findings have also implications for the literature on law and economics. Research within this field has explained high compliance with 'mild' laws - laws which are backed by non-deterrent legal sanctions - by the fact that people are also governed by social norms: legal and informal sanctions together contribute to compliance (Ellickson, 1998; Posner, 2000). If the informal sanctions for the violation of a (legal and social) norm are conditional on the (expected) prevalence of such actions - as suggested by our evidence - it establishes a rationale for conditional compliance with laws. 'Broken windows' (Wilson and Kelling, 1982), i.e. signals on other's non-compliance, might then shape beliefs about the expected social, rather than legal sanctions. In this way, our results neatly fit to the recent evidence in Keizer et al. (2008), who show that signs of norm violations trigger further violations of legal regulations even if the signs are likely not to influence expectations regarding legal sanctions. More generally, our findings are also compatible with multiple equilibrium states in criminal activity - in particular, for such petty crimes as stealing newspapers or fare dodging (compare e.g. Glaeser et al., 1996).

While our study provides some first insights into the patterns of norm-enforcing sanctions beyond experimental laboratories, the question regarding the external validity of the survey responses - i.e. to which extent people really engage in social norm enforcement - is left for future research. Thereby, the combination of experimental and survey methods, as discussed in Fehr et al. (2003), appears to be a particularly promising approach. 


\section{Acknowledgements}

We would like to thank Carsten Burhop, Christoph Engel, Roberto Galbiati, Stefan Trautmann, Arthur van Soest and Joel van der Weele for helpful comments. Traxler acknowledges Financial support by the Austrian National Bank (OeNB Jubiläumsfonds Grant No. 12301) and the Marie Curie Research Training Network ENABLE. The usual disclaimer applies.

\section{References}

Alm, James, Gary H. McClelland and William D. Schulze (1992), Why do people pay taxes?, Journal of Public Economics 48(1), 21-38.

Alpizar, Francisco, Fredrik Carlsson and Olof Johansson-Stenman (2008), Anonymity, Reciprocity, and Conformity: Evidence from Voluntary Contributions to a Natural Park in Costa Rica, Journal of Public Economics 92(5-6), 1047-1060.

Babcock, Linda and George Loewenstein (1997), Explaining Bargaining Impasse - The Role of Self-Serving Biases, Journal of Economic Perspectives 11, 109-126.

Coleman, James S. (1990), Foundations of Social Theory, Harvard University Press, Cambridge (MA).

Cinyabuguma, Matthias, Talbot Page and Louis Putterman (2005), Cooperation under the threat of expulsion in a public goods experiment, Journal of Public Economics 89(8), 1421-1435.

Dohmen, Thomas, Armin Falk, David Huffman and Uwe Sunde (2008), Homo Reciprocans: Survey Evidence on Prevalence, Behavior and Success, Economic Journal, forthcoming.

Ellickson, Robert (1998), Law and Economics Discovers Social Norms, The Journal of Legal Studies 27(2), 537-552.

Falk, Armin, Ernst Fehr and Urs Fischbacher (2005), Driving Forces Behind Informal Sanctions, Econometrica 73(6), 2017-2030.

Fehr, Ernst, Urs Fischbacher, Bernhard von Rosenbladt, Jürgen Schupp and Gert G. Wagner (2002), A Nation-Wide Laboratory, Schmollers Jahrbuch 122, 519-542.

Fehr, Ernst and Klaus Schmidt (2006), The Economics of Fairness, Reciprocity and Altruism - Experimental Evidence and New Theories, in: Serge-Christophe Kolm and Jean Mercier Ythier (Eds.), Handbook on the Economics of Giving, Reciprocity and Altruism, Vol.1, North Holland, Amsterdam.

Fellner, Gerlinde, Rupert Sausgruber and Christian Traxler (2007), Legal Threat, Moral Appeal and Social Information - Testing Enforcement Strategies in the Field, Mimeo, Max Planck Institute, Bonn. 
Fischbacher, Urs, Simon Gächter and Ernst Fehr (2001), Are People Conditionally Cooperative? Evidence from a Public Goods Experiment, Economics Letters 71(3), 397-404.

Frey, Bruno and Stephan Meier (2004), Social Comparisons and Pro-social Behavior: Testing 'Conditional Cooperation' in a Field Experiment, American Economic Review 94(5), $1717-1722$.

Gächter, Simon (2007), Conditional cooperation: Behavioral regularities from the lab and the field and their policy implications, in: Bruno S. Frey and Alois Stutzer (Eds.): Economics and Psychology, MIT Press, Cambridge (MA).

Glaeser, Edward L., Bruce Sacerdote and Jose A. Scheinkman (1996), Crime and Social Interaction, The Quarterly Journal of Economics 106, 507-548.

Keser, Claudia and Frans van Winden (2000), 'Conditional Cooperation and Voluntary Contributions to Public Goods', Scandinavian Journal of Economics 102, 23-39.

Keizer, Kees, Siegwart Lindenberg and Linda Steg (2008), The Spreading of Disorder, Science 322(5908), 1681-1685.

Lindbeck, Assar, Sten Nyberg and Jörgen W. Weibull (1999), Social Norms and Economic Incentives in the Welfare State, The Quarterly Journal of Economics 114(1), 1-35.

Posner, Richard A. (2000), Law and Social Norms, Harvard University Press, Cambridge (MA).

Pruckner, Gerald and Rupert Sausgruber (2008), Honesty on the Streets - A Natural Field Experiment on Newspaper Purchasing, Discussion Papers, University of Innsbruck.

Rege, Mari and Kjetil Telle (2004), The impact of social approval and framing on cooperation in public good situations, Journal of Public Economics 88(7-8), 1625-1644.

Sonnemans, Joep, Arthur Schram and Theo Offerman (1999), Strategic behavior in public good games: when partners drift apart, Economics Letters 62(1), 35-41.

Tyran, Jean-Robert and Lars Feld (2006), Achieving Compliance when Legal Sanctions are Non-deterrent, Scandinavian Journal of Economics 108(1), 135-156.

Wilson, James and George Kelling (1982), Broken Windows, The Atlantic Monthly 249, $29-38$.

Wooldrige, Jeffrey M. (2002), Econometric Analysis of Cross Section and Panel Data. Cambridge, MA, and London, UK: MIT Press. 


\section{Tables}

Table 1: Descriptive Statistics for the Covariates

\begin{tabular}{l|rrrrrr}
\hline \hline Variable & $\mathrm{N}$ & Mean & SD & Min & Median & Max \\
\hline Female & 1138 & 0.59 & 0.49 & 0.00 & 1.00 & 1.00 \\
Employed & 1135 & 0.50 & 0.50 & 0.00 & 0.00 & 1.00 \\
\hline Age & & & & & & \\
$\quad$ Age Low (<29) & 1138 & 0.09 & 0.29 & 0.00 & 0.00 & 1.00 \\
$\quad$ Age Mid (30-49) & 1138 & 0.39 & 0.49 & 0.00 & 0.00 & 1.00 \\
$\quad$ Age High (> 50) & 1138 & 0.52 & 0.50 & 0.00 & 1.00 & 1.00 \\
\hline Education & 1138 & 0.27 & 0.44 & 0.00 & 0.00 & 1.00 \\
$\quad$ Edu Low & 1138 & 0.55 & 0.50 & 0.00 & 1.00 & 1.00 \\
Edu Mid & 1138 & 0.19 & 0.39 & 0.00 & 0.00 & 1.00 \\
$\quad$ Edu High & & & & & & \\
\hline Household Net Income & 1114 & 0.13 & 0.34 & 0.00 & 0.00 & 1.00 \\
$\quad$ Inc Low (<€1017) & 1114 & 0.47 & 0.50 & 0.00 & 0.00 & 1.00 \\
Inc Mid (€1017-2024) & 1114 & 0.40 & 0.49 & 0.00 & 0.00 & 1.00 \\
$\quad$ Inc High (>€2024) & & & & & & \\
Contact with Neighbors & 1136 & 0.44 & 0.50 & 0.00 & 0.00 & 1.00 \\
$\quad$ Con Low & 1136 & 0.35 & 0.48 & 0.00 & 0.00 & 1.00 \\
Con Mid & 1136 & 0.20 & 0.40 & 0.00 & 0.00 & 1.00 \\
$\quad$ Con High & & & & & & \\
\hline \hline Belief about Frequency & 1118 & 3.59 & 1.01 & 1.00 & 4.00 & 5.00 \\
$\quad$ Drunk Driving & 1095 & 3.34 & 1.23 & 1.00 & 3.00 & 5.00 \\
Hazardous Waste & 1123 & 4.17 & 0.91 & 1.00 & 4.00 & 5.00 \\
Speeding & 1030 & 3.16 & 1.25 & 1.00 & 3.00 & 5.00 \\
Stealing Newspapers & 1074 & 3.09 & 1.17 & 1.00 & 3.00 & 5.00 \\
Skiving off Work & 1052 & 2.64 & 1.09 & 1.00 & 3.00 & 5.00 \\
Evading Licence Fees & 984 & 2.96 & 1.15 & 1.00 & 3.00 & 5.00 \\
Fare Dodging & 1094 & 3.81 & 1.05 & 1.00 & 4.00 & 5.00 \\
$\quad$ Evading Taxes & & & & & & \\
\hline \hline
\end{tabular}


Table 2: Reaction to an Acquaintance's Norm Violation (in Percentages)

\begin{tabular}{l|rrrrrrrr}
\hline \hline & Drunk & Hazard. & & Stealing & Skiving of & Evading & Fare & Evading \\
& Driving & Waste & Speeding & Newsp. & Work & TV Fees & Dodging & Taxes \\
\hline Would freeze contact & 4.39 & 7.82 & 5.98 & 13.27 & 11.69 & 8.00 & 9.31 & 7.29 \\
Seriously talk about it & 78.65 & 73.11 & 59.40 & 42.88 & 40.07 & 38.22 & 34.36 & 13.27 \\
Would not care & 9.58 & 12.30 & 20.21 & 31.11 & 34.80 & 40.16 & 34.71 & 50.09 \\
Better not be caught & 5.54 & 4.04 & 12.30 & 9.75 & 9.40 & 9.58 & 15.55 & 21.70 \\
Would be impressed & 0.09 & 0.09 & 0.18 & 0.26 & 0.79 & 0.53 & 0.09 & 4.04 \\
\hline No Response & 1.76 & 2.64 & 1.93 & 2.72 & 3.25 & 3.51 & 5.98 & 3.60 \\
\hline \hline
\end{tabular}

Notes: Response in percentages of all participants $(N=1138)$. The survey allowed for only one response per participant. 
Table 3: Ordered Probit Estimations - Dependent Variable: Reaction

\begin{tabular}{|c|c|c|c|c|c|c|c|c|c|c|c|c|c|c|c|c|}
\hline & \multicolumn{8}{|c|}{ Full Sample } & \multicolumn{8}{|c|}{ Restricted Sample (Intermediate \& High Education) } \\
\hline & (1) & $(2)$ & (3) & (4) & (5) & (6) & (7) & (8) & (1) & (2) & (3) & (4) & $(5)$ & (6) & (7) & (8) \\
\hline & Drunk Driving & Hazard.Waste & & Steal.Newsp. & Skiving offWork & Licence Fee & Fare Dodging & Tax Evasion & Drunk Driving & Hazard.Waste & Speeding & Steal.Newsp. & Skiving offWork & Licence Fee & Fare Dodging & Tax Evasion \\
\hline \multirow[t]{2}{*}{ Belief } & -0.047 & 0.03 & -0.059 & -0.095 & -0.081 & -0.078 & -0.062 & -0.204 & -0.087 & -0.006 & -0.119 & -0.115 & -0.086 & -0.113 & -0.109 & -0.234 \\
\hline & {$[1.22]$} & {$[0.94]$} & {$[1.52]$} & {$[3.19]^{* * *}$} & {$[2.75]^{* * *}$} & {$[2.42]^{* *}$} & {$[1.88]^{*}$} & {$[6.17]^{* * *}$} & {$[1.91]^{*}$} & {$[0.17]$} & {$[2.58]^{* * *}$} & {$[3.33]^{* * *}$} & {$[2.49]^{* *}$} & {$[3.12]^{* * *}$} & {$[2.93] * * *$} & {$[5.93]^{* * *}$} \\
\hline \multirow[t]{2}{*}{ Female } & 0.19 & 0.118 & 0.156 & 0.026 & 0.063 & 0.018 & -0.056 & 0.127 & 0.255 & 0.188 & 0.223 & 0.027 & 0.03 & 0.07 & -0.01 & 0.119 \\
\hline & {$[2.35] * *$} & {$[1.50]$} & {$[2.19] * *$} & {$[0.36]$} & [0.89] & {$[0.26]$} & {$[0.77]$} & {$[1.78]^{*}$} & {$[2.63]^{* * *}$} & {$[2.06]^{* *}$} & {$[2.67]^{* * * *}$} & [0.33] & {$[0.38]$} & {$[0.86]$} & {$[0.12]$} & [1.47] \\
\hline \multirow[t]{2}{*}{ Employed } & -0.164 & -0.219 & -0.177 & -0.223 & 0.09 & -0.224 & -0.26 & -0.039 & -0.189 & -0.314 & -0.215 & -0.213 & 0.033 & -0.231 & -0.288 & -0.048 \\
\hline & {$[1.65]^{*}$} & {$[2.31]^{* *}$} & {$[1.93]^{*}$} & {$[2.50]^{* *}$} & [1.09] & {$[2.74] * * *$} & {$[2.84]^{* * *}$} & {$[0.47]$} & [1.58] & {$[2.90]^{* * *}$} & {$[2.02]^{* *}$} & {$[2.12]^{* *}$} & {$[0.35]$} & {$[2.57]^{* *}$} & {$[2.81]^{* * *}$} & {$[0.50]$} \\
\hline \multirow[t]{2}{*}{ Con High } & -0.086 & -0.043 & -0.122 & 0.033 & 0.036 & 0.081 & -0.013 & 0.098 & -0.092 & -0.088 & -0.031 & 0.002 & 0.065 & 0.021 & -0.046 & 0.132 \\
\hline & [0.79] & {$[0.41]$} & [1.29] & {$[0.34]$} & {$[0.38]$} & {$[0.83]$} & [0.13] & [1.06] & {$[0.74]$} & {$[0.72]$} & {$[0.28]$} & {$[0.02]$} & {$[0.62]$} & {$[0.19]$} & {$[0.40]$} & {$[1.25]$} \\
\hline \multirow[t]{2}{*}{ Con Low } & 0.079 & 0.055 & 0.152 & 0.087 & 0.046 & 0.034 & 0.064 & 0.064 & 0.132 & 0.064 & 0.248 & 0.085 & 0.012 & 0.024 & 0.131 & 0.116 \\
\hline & {$[0.88]$} & {$[0.66]$} & {$[1.92]^{*}$} & [1.09] & {$[0.60]$} & {$[0.45]$} & {$[0.78]$} & [0.82] & {$[1.21]$} & {$[0.64]$} & {$[2.66]^{* * *}$} & {$[0.91]$} & {$[0.13]$} & {$[0.27]$} & [1.37] & [1.25] \\
\hline Age High & 0.038 & -0.05 & 0.173 & 0.113 & 0.237 & 0.093 & 0.055 & 0.089 & 0.024 & -0.096 & 0.086 & 0.209 & 0.18 & 0.117 & 0.09 & 0.065 \\
\hline \multirow[t]{2}{*}{ Age Low } & 0.188 & -0.062 & -0.107 & -0.094 & -0.044 & -0.116 & -0.066 & -0.045 & 0.271 & 0.07 & -0.113 & -0.037 & -0.065 & -0.081 & -0.027 & -0.139 \\
\hline & {$[1.63]$} & {$[0.44]$} & {$[0.78]$} & {$[0.79]$} & {$[0.34]$} & {$[0.88]$} & {$[0.50]$} & {$[0.35]$} & {$[1.91]^{*}$} & {$[0.44]$} & {$[0.72]$} & {$[0.28]$} & {$[0.45]$} & {$[0.57]$} & [0.19] & {$[0.96]$} \\
\hline \multirow[t]{2}{*}{ Inc High } & 0.023 & 0.01 & 0.045 & 0.048 & -0.013 & -0.02 & -0.005 & 0.046 & 0.005 & -0.016 & 0.062 & 0.091 & -0.011 & -0.023 & -0.062 & -0.016 \\
\hline & {$[0.26]$} & {$[0.12]$} & {$[0.58]$} & {$[0.63]$} & {$[0.18]$} & {$[0.27]$} & {$[0.06]$} & {$[0.62]$} & {$[0.05]$} & {$[0.17]$} & {$[0.71]$} & [1.08] & {$[0.13]$} & {$[0.28]$} & {$[0.75]$} & [0.19] \\
\hline \multirow[t]{2}{*}{ Inc Low } & -0.029 & 0.021 & 0.124 & -0.095 & -0.038 & 0.048 & 0.021 & 0.013 & 0.037 & 0.011 & 0.135 & -0.026 & 0.118 & 0.198 & -0.042 & 0.082 \\
\hline & {$[0.21]$} & {$[0.17]$} & [1.08] & {$[0.81]$} & {$[0.32]$} & {$[0.42]$} & [0.19] & {$[0.11]$} & {$[0.18]$} & {$[0.06]$} & {$[0.80]$} & {$[0.14]$} & {$[0.67]$} & [1.13] & {$[0.27]$} & [0.49] \\
\hline \multirow[t]{2}{*}{ Edu High } & 0.15 & -0.072 & 0.062 & -0.095 & 0.135 & -0.124 & -0.152 & 0.209 & 0.141 & -0.067 & 0.047 & -0.11 & 0.124 & -0.122 & -0.114 & 0.236 \\
\hline & {$[1.60]$} & {$[0.74]$} & {$[0.67]$} & [0.99] & [1.49] & [1.39] & [1.58] & {$[2.41]^{* *}$} & [1.33] & {$[0.65]$} & {$[0.47]$} & [1.13] & [1.32] & [1.33] & [1.19] & {$[2.64]^{* * *}$} \\
\hline \multirow[t]{2}{*}{ Edu Low } & -0.014 & -0.016 & 0.045 & 0.159 & -0.062 & 0.057 & 0.099 & 0.151 & & & & & & & & \\
\hline & {$[0.13]$} & {$[0.16]$} & {$[0.46]$} & {$[1.72]^{*}$} & [0.69] & {$[0.62]$} & [1.05] & {$[1.71]^{*}$} & & & & & & & & \\
\hline $\mathrm{N}$ & 1077 & 1052 & 1080 & 988 & 1028 & 1010 & 937 & 1041 & 798 & 784 & 799 & 744 & 771 & 750 & 717 & 773 \\
\hline
\end{tabular}

Robust z statistics in squared brackets; $* / * * / * * *$ indicate significance at a 10\%/5\%/1\%-level. All estimations include region dummies (estimated coefficents not reported). 
Table 4: Estimated Evasion Rate in the Respondents' District.

\begin{tabular}{l|cc}
\hline \hline Evasion Rate & Respondents & Percent \\
\hline$<5 \%$ & 97 & 8.83 \\
$5-10 \%$ & 400 & 36.43 \\
$10-20 \%$ & 274 & 24.95 \\
$20-30 \%$ & 138 & 12.57 \\
$>30 \%$ & 189 & 17.21 \\
\hline \hline
\end{tabular}

Notes: The classification correspond approximately to the five quintiles of the distribution of licence fee evasion in Austria at the time of the survey. 
Table 5: Probit and IV Probit Estimations - Dependent Variable: Sanction Dummy

\begin{tabular}{|c|c|c|c|c|c|c|c|c|c|c|}
\hline & (1) & (2) & (3) & (4) & (5) & (6) & (7) & (8) & (9) & (10) \\
\hline & Probit & IV Probit & Probit & IV Probit & Probit & IV Probit & Probit & IV Probit & Probit & IV Probit \\
\hline Item & \multicolumn{2}{|c|}{ Hazardous Waste } & \multicolumn{2}{|c|}{ Stealing Newspapers } & \multicolumn{2}{|c|}{ Skiving off Work } & \multicolumn{2}{|c|}{ Licence Fee Evasion } & \multicolumn{2}{|c|}{ Fare Dodging } \\
\hline Belief & $\begin{array}{l}0.051 \\
{[1.34]}\end{array}$ & $\begin{array}{l}0.146 \\
{[0.70]}\end{array}$ & $\begin{array}{l}-0.129 \\
{[3.86]^{* * *}}\end{array}$ & $\begin{array}{l}-0.382 \\
{[3.51]^{* * *}}\end{array}$ & $\begin{array}{l}-0.122 \\
{[3.59]^{* * *}}\end{array}$ & $\begin{array}{l}-0.531 \\
{[4.70]^{* * *}}\end{array}$ & $\begin{array}{l}-0.083 \\
{[2.25]^{* *}}\end{array}$ & $\begin{array}{l}-0.285 \\
{[1.86]^{*}}\end{array}$ & $\begin{array}{l}-0.052 \\
{[1.42]}\end{array}$ & $\begin{array}{l}-0.229 \\
{[1.84]^{*}}\end{array}$ \\
\hline \multicolumn{11}{|c|}{ First Stage (IV) Results: } \\
\hline Evasion Level & & $\begin{array}{l}0.174 \\
{[5.82]^{* * *}}\end{array}$ & & $\begin{array}{l}0.252 \\
{[8.32]^{* * *}}\end{array}$ & & $\begin{array}{l}0.191 \\
{[6.50]^{* * *}}\end{array}$ & & $\begin{array}{l}0.193 \\
{[6.92]^{* * *}}\end{array}$ & & $\begin{array}{l}0.251 \\
{[8.65]^{* * *}}\end{array}$ \\
\hline $\begin{array}{l}\text { Wald Test } \\
\text { on exogeneity }\end{array}$ & & $\begin{array}{c}0.20 \\
(0.651)\end{array}$ & & $\begin{array}{l}4.79 \\
(0.029)\end{array}$ & & $\begin{array}{l}8.71 \\
(0.003)\end{array}$ & & $\begin{array}{l}1.70 \\
(0.192)\end{array}$ & & $\begin{array}{l}2.06 \\
(0.152)\end{array}$ \\
\hline $\mathrm{N}$ & 1052 & 1052 & 988 & 988 & 1028 & 1028 & 1010 & 1010 & 937 & 937 \\
\hline
\end{tabular}

Notes: Robust z statistics in squared brackets; $*$ / ** / *** indicate significance at a 10\%/5\% / 1\%-level. All estimations include a set of controll variables as displayed in the laft panel of Table 3 (coefficents not reported). Wald Test reports the Chi2 with the according p-values in brackets. 